Article

\title{
Social Media in the Sexual Lives of African American and Latino Youth: Challenges and Opportunities in the Digital Neighborhood
}

\author{
Robin Stevens ${ }^{1,}{ }^{*}$, Jamie Dunaev ${ }^{2}$, Ellen Malven ${ }^{2}$, Amy Bleakley ${ }^{3}$ and Shawnika Hull ${ }^{4}$ \\ ${ }^{1}$ School of Nursing, University of Pennsylvania, PA 19104, Philadelphia, USA; E-Mail: robin2@nursing.upenn.edu \\ ${ }^{2}$ Department of Childhood Studies, Rutgers University-Camden, Camden, NJ 08102, USA; \\ E-Mails: jamie.dunaev@gmail.com (J.D.), emm272@camden.rutgers.edu (E.M.) \\ ${ }^{3}$ Annenberg School for Communication, University of Pennsylvania; PA 19104, Philadelphia, USA; \\ E-Mail: ableakley@asc.upenn.edu \\ ${ }^{4}$ Milken Institute School of Public Health, The George Washington University, Washington, DC 20052, USA; \\ E-Mail: sjhull@gwu.edu \\ * Corresponding author
}

Submitted: 8 December 2015 | Accepted: 11 March 2016 | Published: 16 June 2016

\begin{abstract}
There has been significant interest in the role of social media in the lives of adolescents, particularly as it relates to sexual risk. Researchers have focused on understanding usage behaviors, quantifying effects of social media exposure and activity, and using social media to intervene. Much of this work has focused on college students and non-minority youth. In this paper, we examine the growing body of literature around social media use among US minority youth and its intersection with sexual risk behavior. We introduce the concept of the "digital neighborhood" and examine the intersection of social media and sexual health in two domains: 1) sexual content in social media and 2) evidence of social media effects on sexual behavior. Finally, we discuss the opportunities and challenges for researchers and practitioners engaging youth of color.
\end{abstract}

\section{Keywords}

African-American; digital neighborhood; health disparities; Latino; sexual health; social media; youth

\section{Issue}

This article is part of the issue "Adolescents in the Digital Age: Effects on Health and Development", edited by Dan Romer (University of Pennsylvania, USA).

(C) 2016 by the authors; licensee Cogitatio (Lisbon, Portugal). This article is licensed under a Creative Commons Attribution 4.0 International License (CC BY).

\section{Introduction}

Despite continued intervention efforts, African American and Latino youth report considerably younger ages of sexual debut and face significantly greater risk for Human Immunodeficiency Virus (HIV) and other sexually transmitted infections (STIs) when compared to their white peers. Health disparities are especially pronounced within the African American adolescent population. In 2011, African American youth accounted for $15 \%$ of the US population aged 13 to 19 years, yet they represented $67 \%$ of HIV diagnoses in this age demographic (Centers for Disease Control and Prevention
[CDC], 2013). African American adolescents are more likely to contract an STI (e.g., Gonorrhea, Chlamydia, or Syphilis) than white adolescents, even when controlling for socio-demographic variables and risky sexual behavior (Centers for Disease Control and Prevention, 2012; Dariotis, Sifakis, Pleck, Astone, \& Sonenstein, 2011). While Hispanic youth face a lower risk of HIV/STI infection than African American adolescents, the risks for Hispanic adolescents are still higher than that of white youth (CDC, 2012). Though African American youth are at an elevated risk for HIV/STIs, they also report higher levels of condom use and lower sexual frequency than their white counterparts (Aral, Adimora, \& 
Fenton, 2008; Hallfors, Iritani, Miller, \& Bauer, 2007). These statistics suggest that sexual health disparities are driven not solely by individual behavior, but also by social determinants that shape the context in which youth make sexual decisions (Adimora, Schoenbach, \& FlorisMoore, 2009; Aral et al., 2008; Hallfors et al., 2007).

One strategy for addressing health disparities experienced by youth of color is to identify and address the social determinants of sexual health, particularly related to the social context in which sexual decisionmaking occurs. One prominent yet understudied social determinant is an adolescent's online community, which we term the "digital neighborhood" (Stevens, Gilliard-Matthews, Dunaev, Woods, \& Brawner, 2016). We emphasize the digital neighborhood, rather than social media use generally, to reflect the digital space that is instrumental in the lives of adolescents. This digital space serves as a nexus for social relationships, entertainment, and geographic neighborhoods. In this paper, we discuss the digital neighborhood as a source of information about sex and sexual health, as well as the prevalence and types of sexual content in the digital neighborhood, and evidence of social media effects on sexual behavior. We also outline opportunities and challenges for working in the digital neighborhood to conduct public health initiatives for youth of color.

\section{Methods}

An extensive search of the literature was conducted using a number of academic databases (e.g., Google Scholar, PsychINFO, PubMed). The following search terms were used: teen, adolescent, youth, African American, Black, Hispanic, Latino, minority, race, media, online, internet, social media, Facebook, Twitter, Instagram, social networking, pornography, sex, sexual health, sexual health information, sex behaviors, and sexual health interventions. Studies were included if they: 1) centered on adolescents/young adults, 2) addressed the topics of sex or sexual health and internet or social media use, and 3) were conducted relatively recently (i.e., in the past decade). In addition, we explicitly sought out papers with substantial minority adolescent samples in the United States.

\section{Social Media Use and the Digital Neighborhood}

Social media are a dominant force in the lives of adolescents. Generally defined, social media are the creation, sharing, and/or communication of content among individuals through digital technologies. It is situated as a unique space where normative influences via social interactions and media influences converge. An estimated $71 \%$ of teens use more than one social media site, with Facebook being the most used site (71\%), followed by Instagram (52\%), Snapchat (41\%), and Twitter (33\%) (Lenhart, 2015). There are demographic differ- ences in social media use, with female adolescents reporting greater use than their male counterparts (Lenhart, 2015). While use of Facebook is approximately the same across racial/ethnic groups, African American youth report more frequent use of Instagram (64\%) compared to white (50\%) and Latino $(52 \%)$ youth. Further, African American youth also report higher Twitter usage $(45 \%)$ than their Latino (34\%) and white (31\%) peers (Lenhart, 2015).

Beyond frequency of usage, the role of social media in the lives of minority youth is greatly understudied. The few extant studies on this topic suggest youth of color may use social media in ways that are different from white youth. While most adolescents may use the same social media platforms (e.g. Twitter, Facebook), their activities on these sites and the content to which they are exposed can differ vastly. For instance, recent qualitative findings suggest that low income minority teens report behaviors on social media related to aggression, violence, and sexuality that mirror community level risk factors (Patton, Eschmann, \& Butler, 2013; Stevens, Gillard-Matthews, Nilsen, Malven, \& Dunaev, 2014). Thus, risk factors in adolescents' offline worlds may be amplified in their online communities, and vice versa. Based on our own work with minority youth, we developed the concept of the "digital neighborhood" to describe these complex online environments and interactions (Stevens et al., 2016).

The digital neighborhood is the online community that adolescents cultivate and are exposed to through their use of various social media platforms. The digital neighborhood parallels that of their built geographic environment and offline social relationships, yet is not completely bound by geography. Unlike the geographic neighborhood, the digital neighborhood is distinct for every youth. Further, just as the built environment can affect health through a variety of mechanisms, the digital neighborhood also influences attitudes, beliefs, sexual opportunities and behaviors. The digital 'hood' functions as a space where youth share and seek out sexual information, as well as a space where people model sex-related behaviors, and where norms are depicted, circulated, and amplified or weakened. As such, we consider the digital neighborhood to be a social, albeit digital, determinant of health. Considering the aforementioned sexual risks (e.g., HIV, STIs) faced by minority youth, it is of vital importance to understand the role of the digital neighborhood in their sexual decision making processes.

\section{Sexual Content in Social Media}

Adolescents seek out and encounter sexual content online in a number of forms including sexually explicit material, information about sex, sexual health, and sexual norms, and sexual communications via social networking sites. This sexual content may take the 
form of text, images, or videos, and the content itself ranges from humorous memes and information about birth control to graphic pornography. The amount, variety, and explicitness of this sexual content varies based on each youth's online behavior and specific digital neighborhood. Considering this miscellany of content, it is important to discuss what types of sexual content adolescents are accessing online, particularly minority adolescents.

The internet serves as an important space for adolescents to obtain information about sexual health. While parents and friends have traditionally been cited as the most common sources of information about sex, the internet is becoming an increasingly popular information source (Bleakley, Hennessy, Fishbein, \& Jordan, 2009; Dolcini, 2014; Stevens, Gilliard-Matthews, Dunaev, \& Todhunter-Reid, 2015). A recent review found that youth most commonly sought information on the following topics: HIV/AIDS/STIs, pregnancy/childbirth, sex acts/behavior, contraception/protection, information about the body, relationships/social issues, and sexual identity and orientation (Daneback, Sevcikova, Mansson, \& Ross, 2013; Kanuga \& Rosenfeld, 2004; Simon \& Daneback, 2013). Adolescents also used the internet to obtain information that is not traditionally included in sexual education such as pleasure-based sex, masturbation, and sex positions (Daneback et al., 2013). One study using semi-structured interviews with African American adolescents living in low-income neighborhoods in Chicago found that $47 \%$ of participants had obtained sexual health information online. Specifically, teens in the study reported seeking out information about HIV/STIs (e.g., testing, treatment, general information), condoms, birth control methods, and sexual communication/relationships (Dolcini, Warren, Towner, Catania, \& Harper, 2015).

The internet may serve as a space for adolescents to access sexually explicit material. Sexually explicit websites (SEWs), as defined by Braun-Courville and Rojas (2009), are "X-rated or pornographic websites that either: describe people having sex, show clear pictures of nudity or people having sex, or show a movie or audio that describes people have sex" (p. 157). While general data on adolescents shows that $42 \%$ of internet users aged 10 to 17 years report being exposed to online pornography in the past year, these estimates may be higher among minority youth (as cited in Braun-Courville \& Rojas, 2009). In a survey among urban Hispanic and African American adolescents $(N=433), 55.4 \%$ of the participants reported having ever visited a sexually explicit website (Braun-Courville \& Rojas, 2009).

Third, the proliferation of social media platforms in recent years has given youth new means for sexrelated communication and self-expression. A youth's digital neighborhood may be particularly important, considering that it can be a space free from adult sur- veillance in which youth can experiment with their identities and express themselves in varied ways (Livingstone, 2008). Youth may engage online in a number of ways, including by posting or sharing sexual images or content and by joining groups or relevant discussions. Based on recent studies, it is estimated that between $25 \%-33 \%$ of youth collect and distribute content and information pertaining to sex online (Bobkowski, Brown, \& Neffa, 2012; Doornwaard, Moreno, van den Eijnden, Vanwesenbeeck, \& Ter Bogt, 2014; Moreno, Briner, Williams, Walker, \& Christakis, 2009; Moreno, Briner, Williams, Brockman, Walker, \& Christakis, 2010; Moreno, Parks, Zimmerman, Brito, \& Christakis, 2009). This content may communicate idealized images, peer norms or model behavior (De Ridder \& Van Bauwel, 2013)

The amount of sexual disclosure or sexually-explicit material shared on social media also varies substantially between samples of American adolescents. JordánConde, Mennecke, and Townsend (2014) found that of the social media posts made by adolescents during a study, only $4.6 \%$ pertained to sexual behavior. In contrast, Moreno, Briner, Williams, Brockman, Walker, \& Christakis, (2009) reported that nearly $25 \%$ of adolescent social media posts contained sexual references. Further, research suggests females are considerably more likely to self-disclose sexual information than males, both on social media and offline contexts (Allison et al., 2012; Brown \& Bobkowski, 2011; Moreno, Parks, et al., 2009). Although African American and Latino adolescents were represented to some degree in the majority of studies under review, these groups typically made up fewer than $25 \%$ of participants. Thus, less is known about the behaviors of minority youth in particular on this topic.

Multiple studies also demonstrate that teens are hyper-aware of the public nature of their social media profiles, with users frequently commenting on sexual attractiveness, or lack thereof, when peers post provocative photos (Manago, Ward, Lemm, Reed, \& Seabrook, 2015; Ringrose \& Renold, 2012; Stevens et al., 2014). This anticipation of appreciative or negative feedback causes some adolescents to avoid posting photos of themselves, while others post sexually suggestive image to gain "likes," in what Magano deems "self-commodification" online (Manago, Graham, Greenfield, \& Salimkhan, 2008; Manago et al., 2015; Stevens et al., 2016).

Finally, social media provide youth with a tool for seeking out romantic partners. There are a number of platforms that facilitate these interactions, including online dating sites (e.g., MyLOL.com; bebo.com), geosocial networking sites (e.g., Skout, Blendr, Grindr), sites where youth can engage in sex-based role playing, and apps for sharing sexually-explicit images online (e.g., Snapchat, sexting, emailing nude photos) (Gabarron, Serrano, Wynn, \& Lau, 2014; Holloway, Dunlap, 
Del Pino, Hermanstyne, Pulsipher, \& Landovitz, 2014; Jordán-Conde, Mennecke, \& Townsend, 2014; Moreno, Parks, et al., 2009; van Oosten, Peter, \& Boot, 2015). While many of these sites are relatively new and thus less is known about adolescent users, there is some preliminary evidence to suggest they are important points for future study. In a sample of youth $(N=273)$, Buhi et al. (2013) found that $15 \%$ of teens reported meeting someone first online before later having sex with them. Among these teens, 57\% reported having met more than one sex partner online. Continued investigation into social media uses is therefore needed as new sites appear, platforms change, and youth usage behaviors evolve, particularly with diverse samples of youth, as these behaviors likely differ based on social and demographic subgroups.

\section{Theoretical Paradigms and Mechanisms of Influence}

Adolescents' sexual decision making is impacted by various sociocultural influences, including their social environment, parents, peers, neighborhood, and new and traditional media (Bleakley, Hennessy, Fishbein, \& Jordan, 2008; Brown et al., 2006; DiClemente, Salazar, Crosby, \& Rosenthal, 2005; Stevens et al., 2014). Social media are positioned at the intersection of traditional broadcast media, the social environment, and interpersonal communication between significant others (e.g., peers, sexual partners, and parents), and as such may have a particularly powerful influence. One way that social media may influence adolescents' attitudes and behaviors is by acting as a 'super peer' (Brown, Halpern, \& L'Engle, 2005; Cookingham \& Ryan, 2015; Moreno, Briner, et al., 2009). Similar to the way one's peers may influence attitudes and behaviors, a "super peer" also conveys social norms and models behaviors, with "super" suggesting an influence that may exceed the influence of traditional peers. Social media sites can act as a super peer, as they are used by youth to create, seek, and share sex-related information and content with known and unknown peers.

The Reasoned Action approach is another useful framework to explain the mechanisms through which the digital neighborhood may influence sexual behavior (Fishbein \& Ajzen, 2010). Sexual behaviors (both risky and safe) are influenced by intentions to engage in those behaviors, attitudes toward the behaviors, selfefficacy, and normative beliefs about the behavior. All of these classes of psychosocial predictors-attitudes, norms and self-efficacy-can be influenced through messages and behaviors received via social media.

More recently, Doornwaard, Bickham, Rich, Ter Bogt, and van den Eijnden (2015) proposed a model that integrates receptive (e.g., sexually-explicit material) and interactive (e.g., social media) online behaviors with perceived peer norms (e.g., perceptions of peers approving of sexual behavior or peers being sexually active) for predicting adolescents' sexual behaviors (Doornwaard et al., 2015). According to this model, sexually explicit internet material and social media use affect sexual behaviors both directly and indirectly through perceived peer norms. Also, adolescents' sexrelated online behaviors, and their perceived peer norms, are associated with adolescents' levels of sexual experience (Doornwaard et al., 2015). While not extensively tested, this model could prove useful in examining the multiple routes and interrelated influences between sex-related online content and offline sexual behaviors.

\section{Social Media Influence on Adolescent Behaviors and Attitudes}

A substantial number of studies have examined the influence of the internet on sexual attitudes and behaviors. Several studies have demonstrated associations between exposure to sexual content and a variety of adolescent sexual attitudes and behaviors (e.g., risky sexual behaviors, casual sex, aggressive sexual behaviors) (see Ybarra, Strasburger, \& Mitchell, 2014). For instance, Bleakley et al. (2009) found that youth who learned about sex from the internet held stronger selfefficacy beliefs (i.e., belief in one's ability to have sex). However, this study also provides evidence of a reciprocal relationship between sex-related content in media and risky sexual behaviors, whereby sexually experienced adolescents seek out sexual content in their media diets, and more sexualized media exposure is associated with increased sexual activity (Bleakley et al., 2009). Thus when considering these effects, it is important to consider the potential for recursive relationships and reverse causality.

The vast majority of research examining associations between online sexual content and adolescent attitudes and behaviors has focused on sexually explicit material (e.g., internet pornography). Exposure to sexually explicit websites was significantly associated with several sexual risk behaviors including multiple sexual partners, anal sex in general, and sexual intercourse with substance use (Braun-Courville \& Rojas, 2009; for review see Owens, Behun, Manning, \& Reid, 2012). However, these findings are not without challenge, as other studies have failed to find any association between viewing sexualized online material and age at first intercourse or having ever had intercourse, and condom use (Braun-Courville \& Rojas, 2009; Ybarra et al., 2014). While these data are surely important, and exposure to sexually explicit content constitutes an important part of an adolescent's digital neighborhood, the focus of this review is on studies examining the effects of social media sexual content on adolescent sexual attitudes and behaviors.

Experimental and network studies suggest that so- 
cial media are particularly influential on perceived norms. In a study of late adolescents ( $M_{\text {age }}=19.2$ ), Young and Jordan (2013) had participants $(N=49)$ view profile pictures of their Facebook friends within their college network. These photos had been rated as being low in prevalence of sexually-suggestive content prior to the study. Participants in the control condition completed a questionnaire without viewing any photos. Results indicated that-compared to a no-photos condition-participants who viewed low prevalence profile photos estimated that a larger proportion of their peers both use condoms and intend to use condoms in the future (Young \& Jordan, 2013). In the second study of late adolescents $\left(M_{\text {age }}=19.6\right)$ also conducted by Young and Jordan (2013), participants $(N=154)$ were randomly assigned to view sexually-suggestive or nonsexually-suggestive photos taken from Facebook. Results indicated that participants in the sexuallysuggestive photo condition, when compared to the nonsexually-suggestive photo condition, estimated that a greater number of their peers engaged in unprotected sex and had sex with strangers. Additionally, participants in the sexually-suggestive photo condition reported greater intentions to engage in these types of behaviors. Taken together, these studies demonstrate that the level of sexual content on social media may affect perceived norms and behavioral intentions (Young \& Jordan, 2013). It would be useful to apply similar study methods to understand the ways in which social media may affect normative perceptions related to sex and sexual health among minority youth in particular.

In a study with an ethnically diverse sample, Black, Schmiege and Bull (2013) analyzed the social networks of 1,029 adolescents in 162 non-overlapping networks. They found that adolescents perceived their peers to be engaging in more risky sexual behaviors than they actually were. Adolescents in the study tended to overestimate the prevalence of high-risk behaviors among peers, while under-estimating the prevalence of protective behaviors among peers (Black et al., 2013). Though the study participants were ethnically diverse, potential moderating effects of race were not reported. While this study importantly demonstrates the discordance between adolescents' perceptions of peers' behaviors and peers' actual behaviors, it fails to shed light onto how minority youth's digital neighborhoods may impact their normative perceptions. Research related to normative perceptions suggests that the effects of norms are, in part, determined by perceptions of similarity to the reference group. Given that one's social network is self-constructed, group identity may be particularly strong for youth of color in the context of social media.

A limited number of studies have also examined associations between internet use, including social media use, and actual behaviors. In a sample of African American adolescents, greater general frequency of internet use (which included social media) was associated with a history of oral, vaginal, or anal sex, and sensation seeking (Whiteley et al., 2011). It should be emphasized, however, that this study did not examine the influence of social media independent of other online sources. In another study using an ethnically diverse sample of adolescents (58\% white, 16\% Hispanic, 15\% African American), Buhi et al. (2013) found that meeting a sexual partner online (through social media or other means), compared to adolescents who had not had sex with a partner met online, was associated with increased sexual risk behaviors (e.g., higher number of vaginal sex partners, lower age of sexual initiation) but not incidence of STIs. Thus research should continue to investigate these paths from internet and social media use to sex-related beliefs, norms, attitudes and behaviors, especially among minority youth.

\section{Social Media Based Sexual Health Interventions}

To the best of our knowledge, there are very few published sexual health interventions that utilize social media as part of the intervention rather than as a recruitment tool. More frequently, interventions incorporate mobile phones, SMS (text) messaging, and webbased components to recruit and retain youth. Of the social media-based interventions that are evaluated, most focus on adults, men who have sex with men, and white or international populations.

Based on the emergent evidence, there is clear potential for effective sexual health promotion interventions that leverage social media. In a systematic review of the impact of social media or text-based sexual health interventions, Jones, Eathington, Baldwin and Sipsma (2014), found that interventions were effective at increasing sexual health knowledge, as well as some evidence of increased condom use (Jones et al., 2014). However, the behavioral effects were mixed and typically short term. Only three of the eleven studies reviewed utilized social media in the interventions while the rest focused on text messaging. Yonker, Zan, Scirica, Jethwani and Kinane, (2014) also conducted a comprehensive review of social media interventions to improve adolescent health (Yonker et al., 2014). Three interventions included significant minority populations (above 50\%) and three evidenced short-term increases in sexual risk-reduction behaviors including seeking information about STI testing and increased condom use (Bull, Levine, Black, Schmiege, \& Santelli, 2012; Moreno, VanderStoep, et al., 2009; Young et al., 2014). In Young et al's (2014) Project HOPE study, 112 predominately African American men who have sex with men participated in a peer-delivered cluster randomized control trial via a private Facebook page. The intervention was designed to utilize social networks to strengthen connections. The intervention group was significantly more likely to increase their sexual risk- 
reduction behaviors. Though this study was conducted with adults, the findings suggest promise for conducting similar work with youth. In a second Facebookbased intervention, Bull et al. (2012) targeted diverse youth utilizing a private Facebook page and a randomized control trial design. There was significant attrition in both the control and intervention groups over the six months post intervention. Participants who received the intervention increased their condom use at twomonth follow-up, though the intervention effects waned at six-month follow-up (Bull et al., 2012). In an HIV prevention intervention with homeless youth, Rice, Tulbert, Cederbaum, Adhikari and Milburn (2012) used peer leaders to reach a hard to reach population, utilizing social media to activate and strengthen social networks. These studies highlight the potential for using social media to improve sexual health among youth of color.

\section{Opportunities and Challenges}

The digital neighborhood is a youth context that offers great promise for conducting both descriptive and intervention research. Social media can be used to describe performance culture, youth norms, and behaviors related to sex and sexual health. It can also be used as a vehicle for recruitment, retention, engagement and intervention. However, working in this domain is not without challenges. The following points enumerate the key opportunities and challenges for work in the digital neighborhood:

\subsection{Methodological Challenges}

Conducting social media-based research among potentially hard to reach and/or minority populations can present several challenges. The first is determining the appropriate, rigorous, and feasible methodological approach. For example, should we adapt social network analyses, socio-linguistic analysis or natural language processing methods for use in this type of research? The evolving nature of social media offers exciting opportunities for researchers from a variety of disciplines to apply their expertise to measuring content, exposure, and potential mechanisms of influence on behavior, as well as the interplay between the digital and offline world.

\subsection{Recruitment and Retention}

Social media interventions give researchers the opportunity to work with youth across the country and the ability to disseminate information on a large scale. As such, it is an increasingly popular recruitment and retention tool (Allison et al., 2012). Researchers will have to balance the challenges of working in this environment, which include participant verification, target population access, and differential attrition rates. In her sampling strategy, Moreno, VanderStoep et al. (2009) recruited high-risk youth by using residence in high-poverty neighborhoods as a recruitment strategy, treating geography as a proxy for risk. Sampling strategies should be designed with potentially elevated attrition in mind.

\subsection{Authenticity of Participants}

Social media offer the research and practitioner community relatively low-cost access to youth. The price of this access is the challenge of verifying the authenticity of potential participants. Studies have tried to decrease non-eligible enrollees by 1 ) enrolling people face-toface, 2) requiring identification or other forms of authentication (i.e. PayPal accounts), or 3 ) by removing monetary incentives for participation to dissuade imposters from enrolling (for a detailed description, see Yuan, Bare, Johnson, \& Saberi, 2014). An additional challenge arises when analyzing exposure to social media content in a network if network members do not consent to be in the study. It may also be difficult to navigate human subjects protections and institutional review board protocols to conduct sexual health research online with minors, where parental consent may not be feasibly obtained.

\subsection{Analysis and Interpretation}

Once a sample is obtained, it may be too large for traditional content analysis. Computerized content analysis utilizing techniques such as natural language processing (NPL) show great promise (Wong et al., 2015). However, these techniques focus on social media language in isolation of conversation. Social media posts are often extended dialogues within youth culture and popular culture. It is important to understand the evolving cultural context in order to correctly interpret social media messages. Interpreting social media messaging outside of the social media conversations where such postings occur can lead to "context collapse." Context collapse occurs when the message intended for a small audience loses meaning when interpreted by an outside audience out of context (boyd, 2008). Qualitative coding of a subsample can limit the likelihood of context collapse and provide rich description of the digital neighborhood, but this approach is difficult to execute with large-scale data sets (Patton et al., 2013).

\subsection{Intervention}

Social media are an important tool in the interventionist's toolbox. They may serve as a complementary component to a face-to-face intervention, a standalone intervention, or a method to gather participant feedback on acceptability and feasibility. The aforementioned Bull et al. (2012) and Young et al. (2014) 
studies were effective even though they employed a closed social network strategy and did not fully capitalize on the dynamism and social networking. Rice et al. (2012) effectively leveraged the social networks and peer leaders using social media to promote HIV prevention among homeless youth. Though more difficult to test, future interventions that can integrate the unique qualities of social media, including extended networks, super peers, and user-generated content, may be particularly innovative and effective.

\subsection{Native Use}

Rather than using social media as a message-delivery tool, the next stage of research that leverages native or naturalistic use of these technologies among youth of color is needed. In addition, finding ways to leverage user-generated content into messages that affect behavior change may be particularly persuasive and relevant (Broaddus et al., 2015; Lelutiu-Weinberger et al., 2014).

\subsection{Multidisciplinary}

Utilizing these dynamic platforms will require the scientific community to work in multidisciplinary teams that include social scientists, practitioners, clinicians, technologists and the youth communities we aim to serve.

\subsection{Youth Engaged}

To be effective, members of the study population should be integrated into research teams, to help interpret the social media content and to inform the team about cultural norms in the digital environment. Community-based participatory research or youth action research approaches may be particularly useful in this context.

\subsection{Digital Neighborhoods Differ}

To develop effective interventions, novelty and innovation will be required as well as integration of the target population at the onset to understand native or intrinsic use of new media, the dynamics of particular social networks, and the intersections of race and gender in the digital neighborhood. Social media are not onesize-fit-all, and intersectionality plays a large part in determining the content and quality of one's digital neighborhood. This will affect the amount of risk messaging and health promotive features that youth are exposed to when they log on.

\section{Conclusion}

Although some progress has been made, more must be done to meet minority youth where they are and im- prove adolescent sexual health for African American and Hispanic populations in the US. It is important to examine the influence of the digital neighborhood on sexual risk behavior and resilience among youth of color, particularly as we consider best practices using technology for intervention. This focus is particularly relevant in light of the paucity of research on social media-use among youth of color, the pervasive use of social media among the population, and the persistent racial disparities in HIV/STI infection. As can be seen, the data on associations between social media usage and adolescent sexual norms and behaviors is limited. Though the research is nascent, existing interventions suggest promise for utilizing social media to improve sexual health among youth of color. With its great popularity among youth, social media-particularly as used by youth of color-are an understudied youth environment where, implicitly or explicitly, beliefs and attitudes are shared, norms transmitted, and behavior modeled. Given its potential impact on the sexual health behavior of youth, it is important to identify how sex is discussed on social media and to measure the association between social media behavior and sexual risk behaviors among minority youth in order to provide insight to improve adolescent health in communities of color.

\section{Acknowledgments}

The authors would like to acknowledge Dr. Dan Romer's helpful comments on an earlier draft of this manuscript.

\section{Conflict of Interests}

The author declares no conflict of interests.

\section{References}

Adimora, A. A., Schoenbach, V. J., \& Floris-Moore, M. A. (2009). Ending the epidemic of heterosexual HIV transmission among African Americans. American Journal of Preventive Medicine, 37(5), 468-471. doi:10.1016/j.amepre.2009.06.020

Allison, S., Bauermeister, J. A., Bull, S., Lightfoot, M., Mustanski, B., Shegog, R., \& Levine, D. (2012). The intersection of youth, technology, and new media with sexual health: Moving the research agenda forward. Journal of Adolescent Health, 51(3), 207-212. doi:10.1016/j.jadohealth.2012.06.012

Aral, S.O., Adimora, A.A., \& Fenton, K.A. (2008). Understanding and responding to disparities in HIV and other sexually transmitted infections in African Americans. The Lancet, 32(9635), 337-340. doi: http://dx.doi.org/10.1016/S0140-6736(08)61118-6

Black, S. R., Schmiege, S., \& Bull, S. (2013). Actual versus perceived peer sexual risk behavior in online youth 
social networks. Translational Behavioral Medicine, 3(3), 312-319. doi:10.1007/s13142-013-0227-y

Bleakley, A., Hennessy, M., Fishbein, M., \& Jordan, A. (2008). It works both ways: The relationship between exposure to sexual content in the media and adolescent sexual behavior. Media Psychology, 11(4), 443461. doi:10.1080/15213260802491986

Bleakley, A., Hennessy, M., Fishbein, M., \& Jordan, A. (2009). How sources of sexual information relate to adolescents' beliefs about sex. American Journal of Health Behavior, 33(1), 37-48. Retrieved from http:// www.ncbi.nlm.nih.gov/pmc/articles/PMC2860278/

Bobkowski, P. S., Brown, J. D., \& Neffa, D. R. (2012). “Hit me up and we can get down". Journal of Children and Media, 6(1), 119-134. doi:10.1080/17482798. 2011.633412

boyd, d. (2008). Taken out of context: American teen sociality in networked publics (Doctoral dissertation.). University of California-Berkeley, CA. Retrieved from http://www.danah.org/papers/TakenOutOfContext. pdf

Braun-Courville, D. K., \& Rojas, M. (2009). Exposure to sexually explicit web sites and adolescent sexual attitudes and behaviors. Journal of Adolescent Health, 45(2), 156-162.

Broaddus, M. R., DiFranceisco, W. J., Kelly, J. A., St Lawrence, J. S., Amirkhanian, Y. A., \& Dickson-Gomez, J. D. (2015). Social media use and high-risk sexual behavior among Black men who have sex with men: $A$ three-city study. AIDS and Behavior. doi:10.1007/ s10461-014-0980-z

Brown, J., Halpern, C., \& L'Engle, K. (2005). Mass media as a sexual super peer for early maturing girls. Journal of Adolescent Health, 36(5), 420-427. doi: http://dx.doi.org/10.1016/j.jadohealth.2004.06.003

Brown, J. D., \& Bobkowski, P. S. (2011). Older and newer media: Patterns of use and effects on adolescents' health and well-being. Journal of Research on Adolescence, 21(1), 95-113. doi:10.1111/j.1532-7795. 2010.00717.x

Brown, J. D., L'Engle, K. L., Pardun, C. J., Guo, G., Kenneavy, K., \& Jackson, C. (2006). Sexy media matter: Exposure to sexual content in music, movies, television, and magazines predicts Black and White adolescents' sexual behavior. Pediatrics, 117(4), 10181027. doi:10.1542/peds.2005-1406

Buhi, E. R., Klinkenberger, N., McFarlane, M., Kachur, R., Daley, E. M., Baldwin, J., . . . Rietmeijer, C. (2013). Evaluating the internet as a sexually transmitted disease risk environment for teens: Findings from the communication, health, and teens study. Sexually Transmitted Diseases, 40(7), 528-533. doi:10.1097/OLQ.0b013e31829413f7

Bull, S. S., Levine, D. K., Black, S. R., Schmiege, S. J., \& Santelli, J. (2012). Social media-delivered sexual health intervention: A cluster randomized controlled trial. American Journal of Preventive Medicine, 43(5),
467-474. doi:10.1016/j.amepre.2012.07.022

Centers for Disease Control and Prevention. (2012). Youth risk behavior surveillance-United States, 2011. Retrieved from http://www.cdc.gov/mmwr/ preview/mmwrhtml/ss6104a1.htm

Centers for Disease Control and Prevention. (2013). Rates of diagnoses of HIV infection among adults and adolescents, by area of residence, 2011-United States and 6 dependent areas. HIV Surveillance Report, 23, 1-84. Retrieved from http://www.cdc.gov/ hiv/library/reports/surveillance/2011/surveillance_R eport_vol_23.htm

Cookingham, L. M., \& Ryan, G. L. (2015). The impact of social media on the sexual and social wellness of adolescents. Journal of Pediatric \& Adolescent Gynecology, 28(1), 2-5. doi:10.1016/j.jpag.2014.03.001

Daneback, K., Sevcikova, A., Mansson, S. A., \& Ross, M. W. (2013). Outcomes of using the internet for sexual purposes: Fulfillment of sexual desires. Sex Health, 10(1), 26-31. doi:10.1071/SH11023

Dariotis, J. K., Sifakis, F., Pleck, J. H., Astone, N. M., \& Sonenstein, F. L. (2011). Racial and ethnic disparities in sexual risk behaviors and STDs during young men's transition to adulthood. Perspectives on Sexual and Reproductive Health, 43(1), 51-59. doi:10.1363/4305 111

De Ridder, S., \& Van Bauwel, S. (2013). Commenting on pictures: Teens negotiating gender and sexualities on social networking sites. Sexualities, 16(5/6), 565-585. doi:10.1177/1363460713487369

DiClemente, R. J., Salazar, L. F., Crosby, R. A., \& Rosenthal, S. L. (2005). Prevention and control of sexually transmitted infections among adolescents: The importance of a socio-ecological perspective-A commentary. Public Health, 119(9), 825-836. Retrieved from http://www.sciencedirect.com/science/article/ B73H6-4G7GFPD-2/2/eaed4569fcce74d3d788af56eb 727c19

Dolcini, M. M. (2014). A new window into adolescents' worlds: The impact of online social interaction on risk behavior. Journal of Adolescent Health, 54(5), $497-$ 498. doi:10.1016/j.jadohealth.2014.02.013

Dolcini, M. M., Warren, J., Towner, S. L., Catania, J. A., \& Harper, G. W. (2015). Information age: Do urban African American youth find sexual health information online? Sexuality Research and Social Policy, 12(2), 110-114. doi:10.1007/s13178-014-0174-5

Doornwaard, S. M., Bickham, D. S., Rich, M., Ter Bogt, T. F., \& van den Eijnden, R. J. (2015). Adolescents' use of sexually explicit internet material and their sexual attitudes and behavior: Parallel development and directional effects. Developmental Psychology, 51(10), 1476-1488. doi:10.1037/dev0000040

Doornwaard, S. M., Moreno, M. A., van den Eijnden, R. J., Vanwesenbeeck, I., \& Ter Bogt, T. F. (2014). Young adolescents' sexual and romantic reference displays on Facebook. Journal of Adolescent Health, 55(4), 
535-541. doi:10.1016/j.jadohealth.2014.04.002

Fishbein, M., \& Ajzen, I. (2010). Predicting and changing behavior: A reasoned action approach. NY: Taylor and Francis.

Gabarron, E., Serrano, J. A., Wynn, R., \& Lau, A. Y. (2014). Tweet content related to sexually transmitted diseases: No joking matter. Journal of Medical Internet Research, 16(10), e228. doi:10.2196/jmir.3259

Hallfors, D. D., Iritani, B. J., Miller, W. C., \& Bauer, D. J. (2007). Sexual and drug behavior patterns and HIV and STD racial disparities: The need for new directions. American Journal of Public Health, 97(1), 125. doi:10.2105/AJPH.2005.075747

Holloway, I. W., Dunlap, S., Del Pino, H. E., Hermanstyne, K., Pulsipher, C., \& Landovitz, R. J. (2014). Online social networking, sexual risk and protective behaviors: Considerations for clinicians and researchers. Current Addiction Reports, 1(3), 220-228. doi:10.1007/s404 29-014-0029-4

Jones, K., Eathington, P., Baldwin, K., \& Sipsma, H. (2014). The impact of health education transmitted via social media or text messaging on adolescent and young adult risky sexual behavior: A systematic review of the literature. Sexually Transmitted Diseases, 41(7), 413-419. doi:10.1097/olq.0000000000000146

Jordán-Conde, Z., Mennecke, B., \& Townsend, A. (2014). Late adolescent identity definition and intimate disclosure on Facebook. Computers in Human Behavior, 33, 356-366. doi:10.1016/j.chb.2013.07.015

Kanuga, M., \& Rosenfeld, W. D. (2004). Adolescent sexuality and the internet: The good, the bad, and the URL. Journal of Pediatric \& Adolescent Gynecology, 17(2), 117-124. doi:10.1016/j.jpag.2004.01.015

Lelutiu-Weinberger, C., Pachankis, J. E., Gamarel, K. E., Surace, A., Golub, S. A., \& Parsons, J. T. (2014). Feasibility, acceptability, and preliminary efficacy of a livechat social media intervention to reduce HIV risk among young men who have sex with men. AIDS and Behavior, 19(7), 1214-1227. doi:10.1007/s10461014-0911-z

Lenhart, A. (2015). Teens, social media \& technology overview 2015. Pew Research Center. Retrieved from http://www.pewinternet.org/files/2015/04/PI_Teen sandTech_Update2015_0409151.pdf

Livingstone, S. (2008). Taking risky opportunities in youthful content creation: Teenagers' use of social networking sites for intimacy, privacy and selfexpression. New Media \& Society, 10(3), 393-411. doi:10.1177/1461444808089415

Manago, A., Ward, L. M., Lemm, K., Reed, L., \& Seabrook, R. (2015). Facebook involvement, objectified body consciousness, body shame, and sexual assertiveness in college women and men. Sex Roles, 72(12), 1-14. doi:10.1007/s11199-014-0441-1

Manago, A. M., Graham, M. B., Greenfield, P. M., \& Salimkhan, G. (2008). Self-presentation and gender on MySpace. Journal of Applied Developmental Psychol- ogy, 29(6), 446-458. doi:10.1016/j.appdev.2008.07. 001

Moreno, M., Briner, L., Williams, A., Brockman, L., Walker, L., \& Christakis, D. (2010). A content analysis of displayed alcohol references on a social networking web site. Journal of Adolescent Health, 47(2), 168175. doi:10.1016/j.jadohealth.2010.01.001

Moreno, M., Briner, L., Williams, A., Walker, L., \& Christakis, D. (2009). Real use or "real cool": Adolescents speak out about displayed alcohol references on social networking websites. Journal of Adolescent Health, 45(4), 420-422. doi:10.1016/j.jadohealth.20 09.04.015

Moreno, M., Parks, M., Zimmerman, F., Brito, T., \& Christakis, D. (2009). Display of health risk behaviors on MySpace by adolescents: Prevalence and associations. Archives of Pediatrics \& Adolescent Medicine, 163(1), 27-34. 10.1001/archpediatrics.2008.528

Moreno, M., VanderStoep, A., Parks, M., Zimmerman, F., Kurth, A., \& Christakis, D. (2009). Reducing at-risk adolescents' display of risk behavior on a social networking web site: A randomized controlled pilot intervention trial. Archives of Pediatrics \& Adolescent Medicine, 163(1), 35-41. doi:10.1001/archpediatrics. 2008.502

Moreno, M. A., Parks, M., \& Richardson, L. P. (2007). What are adolescents showing the world about their health risk behaviors on MySpace? Medscape General Medicine, 9(4), 9.

Owens, E. W., Behun, R. J., Manning, J. C., \& Reid, R. C. (2012). The impact of internet pornography on adolescents: A review of the research. Sexual Addiction \& Compulsivity, 19(1-2), 99-122. doi:10.1080/10720 162.2012.660431

Patton, D. U., Eschmann, R. D., \& Butler, D. A. (2013). Internet banging: New trends in social media, gang violence, masculinity and hip hop. Computers in Human Behavior, 29(5), A54-A59. doi:10.1016/j.chb.2012.12. 035

Rice, E., Tulbert, E., Cederbaum J., Adhikari, A. B., \& Milburn, N. G. (2012). Mobilizing homeless youth for HIV prevention: A social network analysis of the acceptability of a face-to-face and online social networking intervention. Health Education Research, 27(2), 226-36.

Ringrose, J., \& Renold, E. (2012). Slut-shaming, girl power and "sexualisation": Thinking through the politics of the international SlutWalks with teen girls. Gender and Education, 24(3), 333-343. doi:10.1080/09540 253.2011.645023

Simon, L., \& Daneback, K. (2013). Adolescents' use of the internet for sex education: A thematic and critical review of the literature. International Journal of Sexual Health, 25(4), 305-319. doi:10.1080/19317611.2013. 823899

Stevens, R., Gilliard-Matthews, S., Dunaev, J., \& Todhunter-Reid, A. (2015). Beyond Netflix \& Chill: So- 
cial media use and sexual health behavior among minority youth. Paper presented at the Social and Behavior Science Research Network Annual Meeting, John Hopkins University, Baltimore, MD.

Stevens, R., Gilliard-Matthews, S., Dunaev, J., Woods, M., Tadesse, G., \& Brawner, B. (2016). The digital hood: Social media use among youth in disadvantaged neighborhoods. New Media \& Society. doi: 10.1177/1461444815625941

Stevens, R., Gillard-Matthews, S., Nilsen, M., Malven, E., \& Dunaev, J. (2014). Socio-ecological factors in sexual decision making among urban female adolescents. Journal of Obstetric, Gynecologic, \& Neonatal Nursing , 43(5), 644-654 doi:10.1111/1552-6909.12493

van Oosten, J. M., Peter, J., \& Boot, I. (2015). Exploring associations between exposure to sexy online selfpresentations and adolescents' sexual attitudes and behavior. Journal of Youth and Adolescence, 44(5), 1078-1091. doi:10.1007/s10964-014-0194-8

Whiteley, L. B., Brown, L. K., Swenson, R. R., Romer, D., DiClemente, R. J., Salazar, L. E., . . . Valois, R. F. (2011). African American adolescents and new media: Associations with HIV/STI risk behavior and psychosocial variables. Ethnicity \& Disease, 21(2), 216222.

Wong, C. A., Sap, M., Schwartz, A., Town, R., Baker, T., Ungar, L., \& Merchant, R. M. (2015). Twitter sentiment predicts Affordable Care Act marketplace enrollment. Journal of Medical Internet Research, 17(2), e51. doi:10.2196/jmir.3812

Ybarra, M. L., Strasburger, V. C., \& Mitchell, K. J. (2014). Sexual media exposure, sexual behavior, and sexual violence victimization in adolescence. Clinical Pediatrics, 53(13), 1239-1247. doi:10.1177/000992281453 8700

Yonker, L. M., Zan, S., Scirica, C. V., Jethwani, K., \& Kinane, T. B. (2014). "Friending" teens: Systematic review of social media in adolescent and young adult health care. Journal of Medical Internet Research, 17(1), e4-e4. doi:10.2196/jmir.3692

Young, S. D., Holloway, I., Jaganath, D., Rice, E., Westmoreland, D., \& Coates, T. (2014). Project HOPE: Online social network changes in an HIV prevention randomized controlled trial for African American and Latino men who have sex with men. American Journal of Public Health, 104(9), 1707-1712. doi:10.210 5/AJPH.2014.301992

Young, S. D., \& Jordan, A. H. (2013). The influence of social networking photos on social norms and sexual health behaviors. Cyberpsychology, Behavior, and Social Networking, 16(4), 243-247. doi:10.1089/cyb er.2012.0080

Yuan, P., Bare, M. G., Johnson, M. O., \& Saberi, P. (2014). Using online social media for recruitment of human immunodeficiency virus-positive participants: A cross-sectional survey. Journal of Medical Internet Research, 16(5), e117. doi:10.2196/jmir.3229

\section{About the Authors}

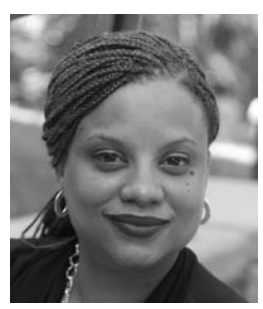

\section{Dr. Robin Stevens}

Robin Stevens, PhD, MPH is a health communication scholar focused on achieving health equity in African American and Latino communities. Her research integrates public health and communication science to influence the individual, social and structural determinants that drive health inequity. Her current studies examine the role of new and social media on adolescent sexual risk and substance use behavior. She is an Assistant Professor at the University of Pennsylvania School of Nursing and directs the Health Equity and Media Lab.

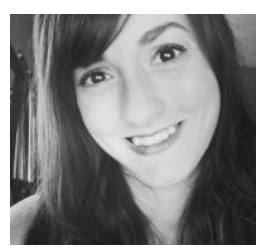

\section{Dr. Jamie Dunaev}

Jamie Dunaev is an Assistant Professor in the Department of Psychology at Rutgers University, Camden. Dr. Dunaev's work examines bias, prejudice, and health disparities, particularly among adolescents.

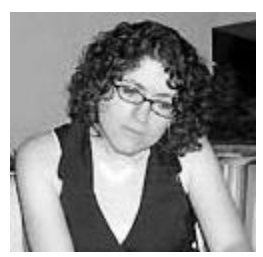

\section{Ellen Malven}

Ellen Malven holds a Masters in English from San Diego State University, and a Masters of Fine Arts in Children's Literature from Hollins University. She is currently researching adolescent perceptions of prosocial media within the Childhood Studies PhD program at Rutgers University in Camden, NJ. 


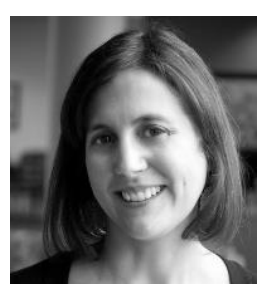

Dr. Amy Bleakley

Amy Bleakley, PhD, MPH, is a senior research scientist at the Annenberg School for Communication at the University of Pennsylvania. Her research focuses on investigating media effects on youth health risk behaviors and health message development and testing.

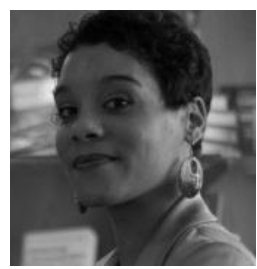

\section{Dr. Shawnika Hull}

Shawnika Hull is an Assistant Professor in the Department of Prevention and Community Health at George Washington University. Dr. Hull's work focuses on using mass mediated communication to affect health beliefs and behaviors. Her work includes the design, implementation and evaluation of mass mediated messages promoting HIV testing among young women of color, raising awareness about PrEP in Milwaukee and DC and promoting acceptance of sexual minorities. Dr. Hull served as the research director for the Acceptance Journeys campaign in Milwaukee. 